\title{
PARECER SOBRE 0 PROJECTO \\ DO \\ DR. INGLEZ DE SOUZA
}

1) No trabalho do profundo jurista patrio Dr. Inglez de Souza, ha tres partes importantes: a transformação do Codigo Commercial em Codigo de Direito Privado, as idéas novas que se contêm no projecto de Codigo Commercial, e, finalmente, a crítica, na Introducção, das idéas que foram vencedoras no actual Codigo Civil. A obra só poderia ser concebida e levada a efteito por um cerebro poderoso, qual o dr. Inglez de Souza, tão grandiosa é. Infelizmente parece que o forcejo do audaz mestre não corresponde ás necessidades sociaes, e foi, na maior parte, em pura perda. E' quasi seguro que se tracta de uma tentativa meramente theorica, uma dessas aventuras perigosas de que fogem os povos, quando não se acham em quadra revolucionaria, ou de profunda transformação social. De algum modo justifica-se o arrojo do grande commercialista, considerando-se que elle se acosta á escola socialista.

Não é porém explicação inteiramente satisfactoria, tendo-se presente o descredito em que cahiram, nestes ultimos tempos, as escolas radicaes do socialismo, permanecendo triumphante a idéa de melhorar, prudente e vagarosamente, o Direito, ao intento de serem protegidos ou auxiliados os fracos na sociedade, sem sacrificio de nenhuma das classes.

2) A unificação do direito privado, locução com que significamos geralmente a fusão do direito civil com o commercial, é apenas um episodio da antiga doutrina, inquestionavelmente mais logica, nascida da revolução francesa, segundo a qual todo o Direito de- 
veria ser reduzido a um codigo geral das leis simples. Chegou mesmo, em 1790, a assembléa constituinte a ordenar que se fizesse um tal codigo, e este projecto foi o germen do futuro Codigo Civil, que era especial, e não geral. O pensamento dominante era estabelecer o codigo social. Com effeito, partindo do direito de igualdade como sendo o unico verdadeiro direito. entendia-se, nesse tempo em que dominou um racionalismo cerebrino, que as regras juridicas prácticas não deveriam ser mais do que o desenvolvimento e a garantia desse unico verdadeiro direito natural, ao ver dos philosophos e estadistas da epoca perfeitamente compativel com o de liberdade.

Foi tal opinião que ainda influiu em nosso grande Teixeira de Freitas, e em nossa Constituição do Imperio, ao prometter um codigo civil e criminal fundado nas solidas bases da justiça e da equidade (art. $179 \S 18$ ).

Só após os trabalhos de Savigny reconheceu-se que o direito é um producto historico, que não se póde enquadrar todo em enormes codigos, que não póde ser simplificado além de certa medida, que acompanha a complexidade crescente da organização social, e que só pela technica juridica póde ter facilitada a applicação, e não pelo seu resumo em enormes corpos de leis ou corligos sociaes. Este modo de ver de Savigny, tão brilhantemente desenvolvido por Ihering, não obstante a rivalidade entre os dois grandes juristas allemães, tornou bem seguro que, em direito, não se póde desfazer o que fez a historia, como não se póde fazer que a arvore se torne de novo semente. E' tempo de renunciarmos a este sonho de simplificação juridica, e contentarmo-nos com os recursos da technica na applicação das leis cujo numero cresce diariamente, produzindo varios ramos na arvore da sciencia juridica. Si, em Roma, numa sociedade rudimentar, não obstante sua decantada cultura, podia a civitas satisfazer-se com um só codigo; complicadas hoje as relações sociaes, separada mesmo a communhão em classes, especializados os cultores do Direito em determinados ramos do saber juridico, já não é possivel actualmente deixar de separar os codigos, de accordo com as classificações scientificas das diversas relações juridicas. 
3) Mas, examinemos como se formou o Direito Mercantil, ao intento de patentearmos que elle não póde vir a receber principios do direito civil, nem se acha sem principios scientificos fundamentaes como pretende o grande mestre Vivante, mestre, é certo, de Direito Commercial, mas jurista classico deslumbrado, fascinado, dominado pela magnitude, pelo brilho, pela offuscante luz que derrama o direito romano, mal de que soffrem mais accentuadamente os italianos pelo grande desenvolvimento que elles dão á sua cultura juridica no estudo do direito romano. Foi ésta exagerada cultura romana que levou um outro luminar das letras juridicas, Cogliolo, a affirmar que, estudado o svstema romano, tinha o jurista conhecimento de toda à evolução juridica, sendo de desprezar os estudos de Direito Comparado feito em povos barbaros!...

4) E' o proprio Vivante quem reconhece que os negociantes, por terem julgado insufficientes as regras romanas para regularem suas transacções, crearam principios consuetudinarios, os quaes, mais tarde, foram reduzidos a leis. Leis são, porém, entende elle, sem um espirito vivificador, "di una grande defizienza nelle regole generale, di una soverchia particolarità nelle norme di vari istituti». O que ha porém, cremos nós, não é falta de principios geraes, a impossibilidade de filiar as regras de direito commercial aos principios de direito civil. A sciencia que Vivante pretende é o impossivel: querer que os principios mercantis, inspirados pela necessidade de rapidez, sejam pelos que, no direito civil, tiveram no intento a segurança e a firmeza dos negocios, é condemnar-se á necessidade de torturar o Direito Commercial, a pretexto de o tornar harmonico com o Direito Civil. Por uma necessidade theorica de igualar os cidadãos, estàbelecendo uma igualdade concreta contrária á verdade, por uma preoccupação de uniformidade nas leis, vamos compor uma legislação que não corresponde ás condições da nossa sociedade, na qual é profunda a differença entre as relações mercantis e as civis. E' certo que, si remontarmos de um principio geral a outro mais geral, até as mais altas generalidades juridicas, encontraremos os mesmos principios communs a todos os ramos do Direito. Pódem servir de exemplo os 
principios fundamentaes apontados por Ahrens, em sua Encyclopedia Juridica (V. I, pags. 206 e segs.) Mas não são esses principios fundamentaes, communs ao direito público e ao privado, que vão servir de elementos para os codigos desejados pelos juristas e pelo povo. Precisamos de regras mais particulares, e, nestas, teremos de estabelecer differença entre o Direito Commercial e o Civil, sob pena de não correspondermos com o codigo á realidade da vida. Regras fundamentaes são iguaes não só nos varios systemas juridicos dos povos cultos, mas até nos dos povos selvagens, por mais rudimentares, toscos que sejam taes systemas, porque, como diz eloquentemente Hermann Post, os principios fundamentaes do direito da humanidade são simples, grandiosos e claros, quanto as leis dos astros. Elles comtudo servem unicamente para integrarem os dos varios ramos do Direito. Os de que precisamos nos codigos não pódem ser unificados sem que tenhamos de forçar a natureza das coisas. Si o Direito Mercantil representa a solução das difficuldades em que se acharam os mercadores, quando reconheceram a insufficiencia do direito commum para bom andamento das transacções commerciaes, claro é que devemos acceital-o como sendo um producto natural, e não nos é licito pretender, com um socialismo radicalissimo, modificar-lhe a formação historica e obrigar negociantes a submetterem-se ás regras de um povo avaro, mesquinho em dinheiro, desprezador de todo progresso mercantil, contrário aos negociantes, qual foi o povo romano.

5) Muito longe leva a paixão, ainda nos mais elevados estudos scientificos. Vivante diz: "Il nostro legislatore chiamò a compilare il nuovo codice gli industriali, i banchieri, gli assecuratori, gli rappresentanti delle grandi sociatà ferroviarie, le camere di commercio, tutrici, anch'esse, del grande commercio, gli uomini che nella professione, nell'insegnamento eranno abituati a difenderni gli interessi, e poi disse ai consumatori : ecco il codice che deve valer anche per voi.» Ora este argumento de Vivante é arma de dois gumes: tambem os negociantes pódem se queixar de que Vivante quer que elles se submettam a uma lei feita por individuos que de commercio nada entendiam. E' argumentação que faz 
lembrar o celebre juiz Magnaud, que permittia aos operarios aquillo que não permittia aos patrões: lançar um operario ao patrão no livro negro, eis um acto de benemerencia para o juiz que os socialistas denominaram bom; lançar porém um patrão a um operario no mesmo livro, eis o que provocava toda a severidade do juiz, que tinha deste modlo duas medidas de julgar.

Quando os negociantes criaram suas normas particulares para regerem as relações mercantis, obraram empiricamente, mas não foi doutro modo que se organizou o Direito Romano, nem tinha elle, no princípio, as fórmas architectonicas com que hoje nos deslumbra. Do mesmo modo por que, em Roma, se luctou pela formação de um systema juridico, lucta tão vivamente descripta por lhering, que lhe dá até uma feição dramatica, assim tambem o direito mercantil vae se formando lentamente ao lado do Direito Civil, assim como se fórma o Direito Administrativo ao lado do Constitucional, assim como se organiza a polícia ao lado da justiça. Direito Commercial, Direito Administrativo, Polícia, são nebulosas donde sahirão systemas juridicos novos. O Direito Commercial se acha em formação, é, relativamente ao Direito Civil, uma criança: como poderemos querer que esteja com principios tão geraes quanto os do Direito Civil? Occorre na sociedade a especie, e é resolvida por uma decisão só applicavel ao caso; repete-se o facto, e a mesma decisão se reproduz; fórma-se a regra com certa generalidade; as regras coordenam-se, subordinam-se; dá-se a integração por principios superiores; constituem-se os institutos juridicos; emfim organiza-se o systema... Isto é obra de seculos, e, em sua instabilidade, exige o Direito contínuas refórmas, retoques em suas várias partes já systematizadas, modificações, achando-se, em summa, em uma constante evoluçâo, como se diz hoje, ou num contínuo devenir, como se dizia quando Hegel estava em moda. Ora, ésta obra secular dos civilistas, está sendo tentada hoje pelos commercialistas, e podemos mesmo dizer que, embora muito distanciado o Direito Mercantil do Civil, encarados ambos do ponto de vista scientifico, já, nalgum de seus institutos, vae o Mercantil no encalço do Civil. Não tem pois razão Vivante em desprezar por ésta fórma o Direito Mercantil, julgando que é elle rude, sem prin- 
cipios, devendo ser enxertado no Civil, para deste receber o influxo scientifico.

6) E' digno de attenção ser o accordo sobre a unificação do direito privado entre Vivante e o Dr. Inglez de Souza acompanhado de desaccordo sobre qual dos dois deva predominar. O Dr. Inglez de Souza, que particularmente se impressiona com a difficuldade cle distinguir os actos mercantis dos civis, inclina-se para o predominio das ideas victoriosas em matéria mercantil. $\mathrm{E}$ ' isto consequencia de sua formação juridica, e tambem da influencia do nos ${ }^{c o}$ meio americano, accentuadamente progressista e reformador, quiçá em excesso, conforme diremos no desenvolvimento deste exame do trabalho do emerito jurista patrio. Provavelmente dahi nasceu a particularidade de ser o nosso jurista contrário á universalização do Direito, quando é partidario da unificação do Direito privado, visto como, é claro, ésta unificação se refere ao direito patrio, extreme dos preconceitos que desfeiam o direito da antiga civilização europea, hoje algum tanto abalada em seu crédito pela conflagração que a desmoraliza, e a universalização sería, de algum modo, nossa subordinação ás idéas da velha Europa.

7) Na doutrina da unificação do direito privado, que não acceitamos, por entendermos que o direito commercial representa a solução de necessidądes que surgiram no seio da vida mercantil, e por julgarmos que será uma preoccupação de gabinete querer sujeitar a vida commercial ás regras creadas para outras relações juridicas, pelo simples amor á regularidade scientifica, ao formalismo, esquecendo os partidarios de tal doutrina que a vida é composta de factos que resistem ás generalizações, como diz Bacon, em tal doutrina, ha, força é reconhecer, um fundo de verdade, e vem a ser que alguns dos institutos hoje regidos por principios civis e mercantis, poderiam, sem grande difficuldade, ser submettidos só ás regras de um desses ramos do Direito. Assim toda hypotbeca, todo penhor poderia ser regido só pelas normas civis. Toda sociedade, toda relação cambial, todo negócio bancario, qualquer relação desta natureza poderia ser regida unicamente pelas re- 
gras do Direito Commercial. O que nos repugna, o que achamos contrário á natureza das coisas, á realidade, á vida, ás conveniencias sociaes portanto, é mesclar principios de origem diversa em um unico corpo de leis, num só codigo.

8) Particularmente não podemos convir na applicação da fallencia aos não commerciantes. Como é reconhecido, e deste parecer é o emerito jurista Dr. Inglez de Souza, a fallencia tem dado pessimos resultados, não obstante as modificações que têm soffrido as leis relativas a este instituto. Não ha interesse em indagar si isto provêm das leis sobre a matéria, si de sua applicação. Estamos de accordo em que, no D. 2024, além de muitos defeitos, geralmente reconhecidos, ha dois capitaes, a saber: pretender-se que os credores habilitados nos primeiros actos da fallencia representam realmente a vontade da maioria dos credores do fallido, e repellir se a acção do juiz, sob o pretexto de que não devem ser tutelados os credores, cuja autonomia não póde a lei pôr em dúvida. Com éstas dúas preoccupações entrega a lei a exploradores de fallencias a sorte da liquidação da massa. Além destes dois vicios da lei, ha a complicação do trabalho da liquidação, a possibilidade de se eternizar a fallencia, sonho dourado dos que vivem de fallencias, dos papa-massas, segundo a pinturesca expressão foren'se. Ora, pela opinião dos unificadores, vamos transportar para o civel ésta calamidade pública que se donomina processo de fallencia, verdadeiro ataque á propriedade dos credores, modalidade do que antigamente se fazia á mão armada nas florestas, tornado hoje o crime, segundo os mestres. mais urbano, adamado, culto e de cidade. Vamos vivendo no civel, menos mal com o nosso concurso de preferencia, com o terrivel labyrintho de credores, e não consta que, em concurso de preferencia, tenha o depositario ficado para sempre com os bens sobre os quaes versava a disputa, conseguindo eternizar o processo.

Mas, quando a fallencia não fosse um assalto aos credores, não fosse coisa muito differente na práctica do que é ensinado nos livros e nas escolas, ainda assim sería, entre nós, de difficil applicação ao civel. Diz o Dr. Inglez de Souza que não ha grande differença entre o 
fazendeiro que explora um immovel com machinas agricolas, tendo a seu serviço centenas ou milhares de operarios, e um negociante. Assim é : mas quantos destes fazendeiros conhece o mestre commercialista brasileiro? $\mathrm{E}$ os milhares de fazendeiros quasi analphabetos que ha em comparação a um desses emprezarios? Como thes applicar a disposição relativa á escripturação de livros, como exigir que tenham papeis em ordem? Ahi têm logar as ideas socialistas do nosso grande commercialista: não podemos applicar a estes homens rusticos (comparados com os negociantes) os preceitos que foram feitos para homens que não pódem deixar de ter alguma cultura, como são os mais modestos negociantes. Infelizmente, ainda os espiritos de escol, e entre estes se acha o Dr. Inglez de Souza, não raro argumentam com suppostos principios scientificos que não correspondem á realidade, ou que não foram formulados por generalizações de factos devidamente observados. Um desses principios perigosissimos é o da igualdade. Sem dúvida, ha a igualdade abstracta, e á Anthropologia devemos ésta importante conquista para o Direito. Todos os homens têm fundamentalmente as mesmas qualidades. Ha entretanto differenças accidentaes, que, por serem accidentaes. não deixam de ser importantissimas, não deixam de influir decisivamente para a alteração das regras juridlicas. Em concreto, não temos igualdade, mas profunda e accentuada desigualdade. Foi o grande erro da revolução francesa querer uma só norma para entes de capacidade muito diversa, e razão teve Bentham quando affirmou que ella chegaria a dar o patrio poder aos filhos, e autorizar os presos a encerrarem nas prisões aos carcereiros...

Si contrária á natureza das coisas é a unificação do direito privado, não offerece tão grandes difficuldades a unificação do processo civil com o commercial, e o motivo disto é que as relações juridicas são submettidas á tela judiciaria já despidas das particularidades da vida civil e da mercantil: um indivíduo que não paga uma letra de cambio está nas mesmas condições ante o juiz, que outro que não paga seu débito hypothecario. Assim mesmo, certos embaraços surgiram, como é sabido, ao applicar-se o R. 737 ao civel, e tivemos de recorrer ao processo antigo para muitas acções de na- 
tureza civil, podendo servir de exemplo as acções possessorias. Concluo pois que podemos estabelecer normas unicamente commerciaes para certos institutos, e o caso não é sem exemplo ra tradição patria, como faz notar o mesmo Dr. Inglez de Soúza; e normas meramente civis para outros, abrandando-se assim a idea da unificação do direito das obrigações e do direito privado (doutrina mais radical), e consequentemente podemos continuar com a unificação processual (civel $\mathrm{e}$ commercial) deixando para o futuro a decisão da vantagem ou desvantagem da unificação do direito privado desejada pelo Dr. Inglez de Souza.

9) Muito mais importante e premente é, a nosso ver, a unificação do processo federal com o estadual, contra o que pensa o Dr Inglez de Souza (pag. 31). E'sta multiplicidade de leis processuaes é que se póde considerar um dos maiores males cla actual organização juridica brasileira. Causa admiração que, contra a opinião quasi unanime dos mestres, venha o Dr. Inglez de Souza negar a magnitude do problema, quando todos se acham de accordo em que é este um dos importantes factores da desunião que se vae accentuando. para mal da nossa patria, entre os diversos estados do Brasil. Só quem está alheio ao movimento forense, á vida juridica, póde contestar a importancia da unificação das leis processuaes. Diremos até que, fóra a lingua, é a unificação processual ao lado do conhecimento da historia patria (1), o factor mais importante da unidade brasileira, unidade por que todos os verdadeiros patriotas anhelamos.

10) Entraremos noutra parte deste estudo. Vamos nos occupar com o Codigo Commercial, onde se admira o grande conhecimento que tem da matéria o illustre mestre. Muitas de suas ideas são excellentes, e quanto ás demais, só me pareceram que são refórmas para fu-

(1) Tão importante quiçá quanto a falta da unidade processual, é a ignorancıa da historia patria, da tradição brasileira: matéria é extranha a este artigo, e por isto não discutiremos seu valor. Reservamos o assumpto para outro artigo a ser publicado nesta Revista, que deve ser uma escola de civismo para a mo. cidade. 
turo muito mais remoto do que suppõe o Dr. Inglez de Souza. Vivante aconselha que os estudiosos, depois de haverem adquirido conhecimento de um instituto do Direito Mercantil, busquem na Bolsa, nos bancos, nas agencias mercantis, o material necessario para bem comprehenderem a estructura e as funcções de tal instituto. Parece que o conselho tem muito mais importancia ainda para as pessoas que pretendem reformar institutos tradicionaes, ou introduzir novos no systema juridico de um povo. O Dr. Inglez de Souza está, em seu Codigo Commercial, muito longe da realidade, não mostra conhecer nosso meio, parece completamente alheio ao nosso movimento commercial, á vida mercantil.

Fixemos como incontestavel que as innovações mais perigosas são as que se entendem com a classe mais atrazada, com os homens de pouca cultura, ou, no caso que nos occupa, com o negociante de pequeno tracto. Menos perigoso é reformar radicalmente a legislação sobre seguros, sobre cheques, sobre abertura de crédito em banco ou em casas de avultado capital, sobre vendas por atacado, do que introduzir a mais leve modificação no modo de vender a retalho, ou nas relações entre empregados e patrões. Vemos a facilidade com que se modificam as leis sobre letras, sobre cheques, sobre constituição de sociedades anonymas, e as luctas, as revoluções ao modificar-se ainda mesmo o systema metrico. E' ésta consideração que, de certo modo, attenúa o perigo das refórmas propostas pelo Dr. Inglez de Souza. Homem de doutrina, advogado de nome, conhecedor das grandes transacções, pouco procurado naturalmente para as pequenas questões mercantis, sua attenção voltou-se, de preferencia, para os institutos que denominarei magnos, e as refórmas que introduz na legislação commercial são, em sua maior parte, tocantes a taes institutos.

11) Tudo quanto propõe relativamente ás modificações da legislação actual sobre debentures, acha-se nestas condiçỗes, pois o instituto é novo, e, como rèconheceu o proprio conselheiro Ruy Barbosa, nosso genial jurista, a lei 177-A de 1893, obra em que o grande brazileiro teve grande parte, está longe de representar a última palavra no assumpto. E' matéria em formação, 
é instituição que effectivamente deve ser retocada. Mas ao ler o que propõe o Dr Inglez de Souza, que vem a ser afinal ampliar a faculdade de emissão e accentuar a repressão dos abusos, assalta logo o espirito ésta pergunta: será prudente tal orientação no Brasil ? Todos sabemos a audacia da especulação entre nós, todos conhecemos a difficuldade da repressão dos abusos, é corrente a phrase quasi proverbial de que ninguem vae aqui para cadeia por fallencia, é sabido que, no nosso meio, não ha attentado contra a propriedade, que, quando com o caracter de especulação de bolsa, não tenha a tolerancia, ou mesmo a sympathia que os espartanos dispensavam aos ladrões dextros.

Ao passo que vemos, em França e em outros paizes, a severidade neste particular extender-se mesmo ao extremo de não se respeitarem homens que bem mereceram da patria, no Brasil é verdadeiro o quadro que o Dr. Octavio Mendes, com tanto vigor, pintou ao criticar o trabalho do Dr. Inglez de Souza (Revista dos Tribunaes, v. 19, pag. 199).

Quanto ao cheque, cujo, desenvolvimento tanto deseja o Dr. Inglez de Souza, nada ha a objectar.

O cheque que, segundo Macleod, não passa de uma modalidade das notas do banco, que suppre o numerario, que, segundo uma fórmula elegante do Dr. Almeidá Nogueira, fixa automaticamente o numerario preciso á vida mercantil de um paiz, será, uma vez desenvolvido, meio seguro para progresso de nossas industrias. Introduzido o uso do cheque na quasi totalidade de nossas transacções mercantis, cessará o motivo de clamarem os especuladores contra a falta de moeda: o cheque suppre a moeda, e só não apparece quando não ha realmente capitaes.

As disposições do Projecto sobre extravio de titulos vêm firmar doutrina sobre o assumpto, e merecem louvadas por sua pureza e sensatez, representando a orientação que vae dominando na sciencia com satisfação de quasi todos os juristas.

O que sustenta relativamente á solidariedade, possivel e mesmo acceitavel no commércio, vem demonstrar a difficuldade que ha em fundir e unificar o direito privado. 
A solidariedade no civel é contrária ás tradições, e será, por seculos, uma constante surpreza, uma verdadeira oppressão aos fracos, uma ruptura na unidade systematica da construcção do direito das obrigações, onde sempre dominou a regra do favor ao devedor. $O$ art. 573 do Projecto, que firma como regra a solidariedade, póde ficar muito bem no Codigo Commercial, mas no Civil será um perigo, uma violencia infundada contra os obrigados.

Em sentido contrário, mostra-se humano o Dr. Inglez de Souza para com os devedores, propondo a quitação da dívida hypothecária pela excussão do immovel, dando á remissão o verdadeiro sentido que deve ter, e favorecendo a cessão de bens. E' de lembrar que, em tal assumpto, temos recuado: o direito romano dos ultimos tempos era muito mais humano do que o actual, que nos rege em pleno seculo 20. Eis preceitos do Projecto que, sem inconveniente, poderiam ser adoptados na vida commercial e na civil. Basta lembrar os casos da restricção romana das vias executivas in quantum facere potest, favor abolido pelo Direito moderno. Não se deve esquecer o que diz o douto jurista cujo trabalho occupa nossa attenção acerca da extensão da remissão que alguns homens duros querem reduzir a uma burla, a um laço armado pela lei á confiança e á ingenuidade do devedor, segundo a linguagem vigorosa de nosso illustre commercialista. E' sabido, e encontra-se em Lobão, que a remissão veio de alguns povos cultos europeus para Portugal, sendo introduzida neste último paiz pelo direito consuetudinario. Lobão a apoia na equidade, como se vê em sua obra Execuções, $\S \S 436$ e segs.

Não desejando insistir noutros pontos de refórma offerecidos pelo nosso commercialista, diremos que chama particularmente a attenção de toda pessoa que se interessa pelo bom andamento dos negocios publicos o que pretende o Dr. Inglez de Souza conseguir em relação ao contracto de locação de serviços. Parece que, neste particular, o importante não é a reforma da legislação substantiva, mas da processual, e mais que tudo do modo de agir dos magistrados. O problema é achar justiça prompta e barata para o trabalhador que só possue o dia e a noite. Este é o problema grave, e 
que tem sido resolvido pessimamente em varios Estados europeus.

No Brasil os juizes complicam e difficultam o processo, de modo que é a acção judicial um luxo só ao alcance dos ricos. Todos sabemos como os juizes de paz applicam o D. 4824, transformando o processo determinado no art. 63 em um monstro muito mais complicado do que o antigo ordinario das nossas ordenações do Reino. Importante tambem é ter estabelecido o projecto a obrigação de indemnização do damno moral: é medida altamente democratica. Neste ponto foi infeliz o nosso Codigo Civil contrário ás ideas do Dr. Inglez de Souza.

Ha um passo do projecto do Dr. Inglez de Souza, que merece reparo: é o referente á procuração em causa propria. Si, com toda a razão, entende que é uma antiqualha, um archaismo sem justificativa, como diz elle, a cláusula, parece que não deveria ter regulamentado tal instituto, estabelecendo ser a procuração irrevogavel, e "ficar o procurador obrigado a dar contas; mas era preferivel, e mais logico, declarar que a cláusula sería tida por não escripta. Teriamos assim em nosso systema juridico, dois institutos bem caracterizados: o mandato e a cessão.

12 Não é possivel deixar sem menção o que diz nosso illustre patricio sobre a marinha e sobre o desenvolvimento de nossos meios de transporte por agua. Ha alguns annos, na America do Norte, fez-se uma campanha para persuardir-nos a grande republica de que deveriamos abandonar a idea de desenvolver nosso commércio maritimo. Argumentavam os americanos com a circumstancia (fálsa) de não termos bons portos. Não é de crer que tivesse ésta propaganda dos nossos amigos da America do Norte tido influencia na accentuada decadencia que se deu em nosso poder maritimo. $O$ que é facto porém é que grande erro tem sido o dos nossos governos de não protegerem o desenvolvimento de nossa marinha, tendo o Brasil immensas costas ameaçadas por nossos irmãos da America e mesmo pelos da Europa, cujos sentimentos pouco humanos estão a patentear-se na conflagração, que mostrou haver mais ap- 
parencia de cultura, do que real desenvolvimento dos sentimentos nobres na humanidade. Tenhamos presente ésta grande verdade proclamada pelo Dr. Inglez de Souza que «é preciso fazer da marinhá mercante a auxiliar valiosa da marinha de guerra.»

Entraremos noutra ordem de considerações.

13) Em refórma de codigos, parece que o mais acertado é que se faça a mudança por partes, á medida que forem sendo exigidas as modificações. Um remendo posto a um fato, um reparo em um predio, desfeiam os objectos. Não succede o mesmo com um codigo: a modificação de nenhum modo the tira a elegancia, ao contrário torna-o mais bello, approxima-o do ideal da perfeição. E' facil de comprehender que um codigo é obra de muitas gerações. Nelle se accumulam as fór mulas juridicas, laboriosamente engendradas, polidas, aperfeiçoadas, como nos mostra Cogliolo, pelos juristas com vocação para esse genero de trabalhos. Ora, quando se faz um codigo novo, mantem-se quasi toda a fórma da lei antiga, e portanto verdadeiramente nunca ha um codigo propriamente novo. O codigo civil frances nada mais é, na sua maior parte, do que a traducção do que estava composto no direito justiniano, que por sua vez, respeitou a fórma da lei das doze taboas. Ha porém sempre ideas novas, para as quaes terá o codificador de buscar novas fórmulas legislativas. Além da fórma, nas ideas novas, ha o conteúdo, que, muitas vezes, collide com o antigo. Uma modificação apparentemente pequena nas ideas juridicas traz alterações profundas no systema juridico. Bruggi cita, para exemplo disto, as notaveis modificações em todas as partes do direito civil italiano pelo simples facto de ser prohibido o trabalho ás crianças até certa edade. Ora, si uma leve modificação, na fórma, ou no fundo, póde alterar grandemente o systema juridico, claro fica quão imprudente é, em um certo momento, fazermos como de empreitada, uma transformação em todo o systema juridico. Um homem, uma geração mesmo, não pócle emprehender sem grande esforço, uma transformação no Direito, no systema juridico. Si possue um codigo, mais acertado é ir tirando o que não mais se acha de accordo com as necessidades novas, ir lentamente substituindo os 
preceitos antiquados por outros que correspondam ás exigencias do pensamento actual, como se fez, com grande vantagem, 'não só em relação ao Codigo Napoleão, mas tambem como se fez, em Roma, relativamente á Lei das Doze Taboas. A Lei das Doze Taboas foi sendo lentamente modificada pelo edito do pretor e pelos trabalhos dos juristas. Justiniano achou a modificação feita, e respeitou, em. sua codificação, até mesmo a fórma do direito novo. O Codigo Napoleão já não tem muito do primitivo. Os artigos foram sendo substituidos por outros, e hoje da veneranda obra de Preameneu pouco resta.

Si a França se lembrar de organizar um novo codigo, nada mais tem do que dar uma nova edição do codigo Napoleão, com todas as correcções e alterações parcialmente feitas no correr do seculo XIX, e não de afogadilho, numa verdadeira mania de reforma.

14) Porque não faremos o mesmo com o nosso Codigo Commercial? Vamos reformando successivamente suas partes defeituosas. Num anno, alteraremos a parte relativa á locação de obras, e veremos o que diz a experiencia a tal respeito. Depois modificaremos o que tem de absurdo quanto ao depósito, e observaremos as consequencias da reforma. Dentro em pouco, sem abalos, teremos modernizado o codigo, que, força é confessar, está muitó atrazado, em consequencia do rapido desenvolvimento que tem tido o Brazil. O projecto do Dr. Inglez de Souza, de uma só vez, estabelece todas as reformas, produzindo profundo abalo na sociedade, coisa que se póde evitar, seguindo o processo de reformas parciaes. E'stas têm ainda a grande vantagem de serem discutidas com maior proveito, pois toda a attenção do legislador se fixa em um só ponto, o ponto que vae ser reformado, e póde então quem formúla o novo preceito verificar quaes as vantagens provaveis de sua adopção, e modificar tambem os outros pontos do codigo que devem ser postos em harmonia com as ideas novas introduzidas no corpo das leis. Poderá o legislador proceder do mesmo modo em relação a um grande numero de reformas? Com muito mais difficuldade o fará.

Por muito bons que tenham sido os resultados produzidos por uma certa lei em paizes extrangeiros, só a 
experiencia poderá dizer si ella dará as mesmas consequencias em nosso paiz. Toda lei tem accentuadamente o caracter de uma experiencia, e as experiencias não pódem ser feitas, sinão com muita prudencia, no corpo social. Uma das medidas de prudencia é justamente a de não serem as experiencias feitas em conjuncto, de uma só vez, mas successivamente. Eis porque não parece seja acceitavel a reforma radical de um codigo, como é o nosso commercial, que, fóra a parte relativa a letras de cambio, hypotheca e sociedades anonymas, está conservado quasi nos mesmos termos em que foi concebido em 1850.

Tenhamos proposito: nem a immobilidare de 67 annos, mantendo preceitos condemnados pela práctica, pelos juizes e pelos homens da doutrina, nem uma reforma subita e radical.

15) Passemos a ver o que diz o illustre mestre acerca do que ha a reformar no Codigo Civil, destinado, segundo seu plano, a fundir-se com o Commercial. Pelo que diz á pag. 93 de sua exposição ao Ministro da Justiça, parece que insignificantes são as modificações que introduz no nosso actual codigo civil (v. 1.․) Logo porém, e pela leitura do volume terceiro, onde se acham as emendas (addições e modificações a serem feitas no Codigo Commercial) para que reja tambem as relações civis, vê-se que profundas são as modificações introduzidas em nosso direito civil tradicional. Tendo, ha pouco, sido promulgado o Codigo Civil, conservador (quiçá em excesso), rão parece razoavel que, antes mesmo de devidamente conhecido, já seja modificado. Isto só tem succedido nas epocas de revoluções, quando a sociedade está convulsionada.

A fundirem-se os dois ramos de Direito privado commercial e civil, forçoso era que, ao menos, respeitassemos o que foi decretado ha pouco, alterando sómente o que fosse absolutamente contrário á vida mercantil. E' certo que o Dr. Inglez de Souza, em alguns pontos, é mais aferrado ao passado do que o Codigo Civil, como por exemplo em relação aos beneficios abolidos em nossa nova lei civil. Em conjuncto, entretanto, é radical, ultra liberal, inclinado ás icleas modernissimas. Tanto mais é condemnavel ésta precipitação, na reforma 
do Codigo Civil recem-nascido, quanto é certo que foi elle recebido com sympathias geraes pelos doutos. Si a nação, por seu escol, está contentissima com uma lei, como abrogal-a, sem ter contra ella mais do que a opinião de alguns commercialistas de que sua fórma perturba a elegancia, a regularidade, a ordem do systema juridico, e, além de a modificar na parte incompativel com a celeridade mercantil, abolir institutos geralmente acceitos nas relações civis, ou crear novos ainda não experimentados?

16) Uma gravissima questão ha a suscitar afinal. Sabem todos que T. de Freitas rescindiu seu contracto com o governo da monarchia, particularmente por um escrupulo mais de cidadão do que de jurisconsulto. Pensava que, em face da letra da Constituição do Imperio, não se podia deixar de fundir o codigo penal com o civil. A Constituição do Imperio mandava organizar um Codigo Civil e Criminal fundado nas solidas bases da justiça e da equidade. Na Constituição da Republica, vemos o contrário, a doutrina opposta. E' ella que, no - art. $34 \S 23$, fala na separação entre o direito civil e o commercial. Poderemos excluir ésta differença entre os dois ramos de direito com sacrificio da segurança dos negocios commerciaes, e da celeridade dos actos mercantis?

Não é só a ésta luz que tem importancia a doutrina da Constituição Federal. Sem dúvida, sendo a Constituição particularmente destinada a definir as garantias que as leis ordinarias deverão dar aos direitos dos membros da communhão social, é importante este ponto de vista em que nos collocamos.

Outro ponto de vista porém temos, e é que, em nossa Constituição actual, não ha, como hâvia na do Imperio, uma parte constitucional e outra não: tudo na actual é constitucional, e uma parte é mesmo considerada fundamental (art. 90).

Emfim, pelo que acima ficou dicto, vê-se que é tradicional ser determinado pelas constituições os termos ou as fórmas fundamentaes dos codigos, parecendo que este motivo historico tem algum peso na interpre- 
tação do artigo da actual constituição referente ás attribuições do congresso legislativo para legislar sobre direito civil e commercial. Tenha-sé presente que cada uma das classes (a commercial e a civil) se julgará prejudicada, e nenhuma entenderá que os prejuizos soffridos por algurs dos preceitos do codigo foram compensados pelas vantagens auferidas em consequencia de outras disposições.

17 Encerrando essas considerações sobre o notavel trabalho do Dr. Inglez de Souza, é nossa conclusão que não deve ser acceito, para ser transformado em lei, mas que deve ser estudado, examinado, criticado, apreciado, porque tem muitas ideas proveitosissimas, ideas que devem ir penetrando lentamente no corpo de nosso systema juridico. Passar, em um só tempo, todas as reformas propostas pelo illustre commercialista para a nossa legislação, é o que constitue uma grave imprudencia. Deixar porém esquecidas todas as suas ideas, muitas das quaes são excellentes, será, ao contrário, sem proposito, ter horror ao progresso.

João Arruda. 